\title{
1. AN \\ Preparation and preliminiar evaluation of new organometallic bases from cis-2,6-dimethylpiperidine
}

\section{Evelyn Mirella Lopes Pina ${ }^{*}$, Natália de Araujo Pereira, Rafael Augusto Soldi, Giuliano Cesar Clososki}

\author{
Research Center for Natural and Synthetic Products - University of São Paulo, Ribeirão Preto-SP \\ *evelyn.mlpd@usp.br
}

Keywords: cis-2,6-dimethylpiperidine, heterocyclic substrates, Negishi cross-coupling

\section{INTRODUCTION}

Recently, magnesiate and zincate reagents have proven their synthetic importance for the functionalization of arenes. ${ }^{1}$ In addition, mixed $\mathrm{Li} / \mathrm{Mg}$ and $\mathrm{Li} / \mathrm{Zn}$ amides prepared from 2,2,6,6tetramethylpyperidine (TMPH) are highly soluble and active bases that allow smoothly metalatation of various aromatic and heteroarenes with an excellent fuctional group tolerance. ${ }^{2}$ In this work, we have been investigating the preparation and the reactivity of mixed metal bases from cis-2,6-dimethylpiperidine (DMPH) as alternative for TMP-metal bases.

\section{RESULTS AND DISCUSSION}

The mixed lithium/magnesium base DMPMgCl.LiCl was prepared in THF through the direct reaction of the cis-2,6-dimethylpiperidine (DMPH) with the turbo Grignard $i$-PrMgCl.LiCl. Titration against benzoic acid using using 4-(phenylazo)-diphenylamine as indicator indicated that the desired base was produced with the concentration of $1 \mathrm{~mol} / \mathrm{L}$. On the other hand, the zinc base DMPZnCl.LiCl was prepared through the reaction of DMPMgCl.LiCl with $\mathrm{ZnCl}_{2}$ in THF (Scheme 1).

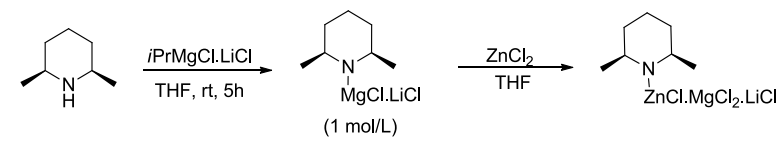

\section{Scheme 1}

In order to investigate the reactivity of the base DMPMgCl.LiCl, we have used isoquinoline as a model substrate (Sheme 2).

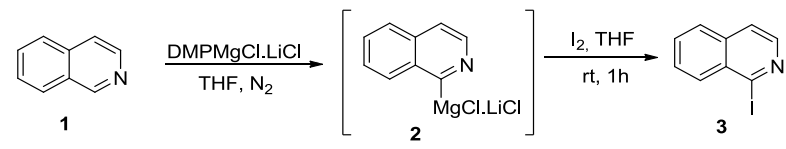

Scheme 2

The metalation was monitored by CG analysis of the aliquots of the reaction mixture that were quenched with iodine. Results are presented in Table 1. As observed, the best conversion was obtained when 2 equiv. of the base was used, leading to the iodide 3 with $89 \%$ isolated yield. This strategy has been applied to the synthesis of other functionalized isoquinoline, some examples are presented in the bellow (Scheme 3).
Table 1. Tests of reaction conditions for the direct metallation with isoquinoline DMPMgCl.LiCl

\begin{tabular}{ccccc}
\hline Entry & $\begin{array}{c}\text { Base } \\
(\mathbf{E q})\end{array}$ & $\begin{array}{c}\text { Reaction } \\
\text { time }\end{array}$ & $\begin{array}{c}\text { Tempera } \\
\text { ture }\end{array}$ & $\begin{array}{c}\text { Conversion } \\
\text { GC }\end{array}$ \\
\hline 1 & 1.1 & $1 \mathrm{~h}$ & r.t. & $35,14 \%$ \\
2 & 1.1 & $3 \mathrm{~h}$ & r.t & $4,91 \%$ \\
3 & 1.3 & $1 \mathrm{~h}$ & r.t & $59,24 \%$ \\
4 & 1.5 & $1 \mathrm{~h}$ & r.t & $88,48 \%$ \\
5 & 1.5 & $1 \mathrm{~h}$ & $0^{\circ} \mathrm{C}$ & $4,66 \%$ \\
6 & 1.8 & $1 \mathrm{~h}$ & r.t & $92 \%$ \\
$\mathbf{8}$ & $\mathbf{2}$ & $\mathbf{1 h}$ & r.t. & $>\mathbf{9 8 \%}$ \\
\hline r.t. = room temperature & & &
\end{tabular}

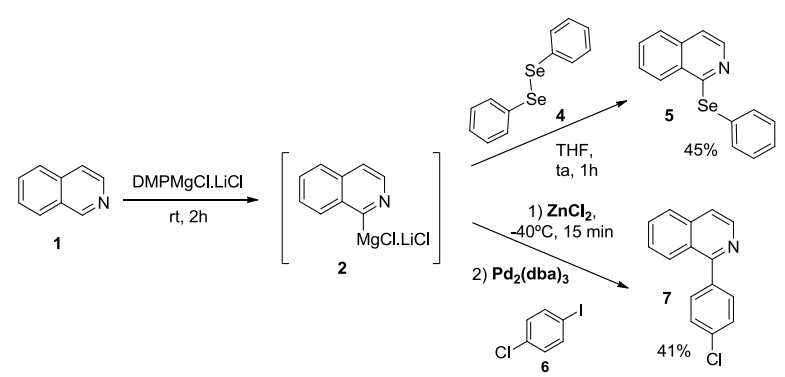

Scheme 3

The zinc base DMPZnCl.LiCl presented low reactivity against the substrate tested. However, organozinc reagents of type 9 could be prepared by using the strategy presented bellow (Scheme 4).

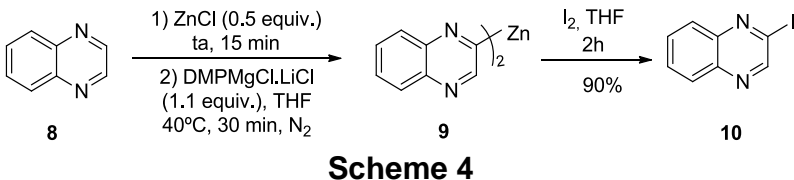

CONCLUSION

The base DMPMgCl.LiCl has been prepared and presented good reactivity for the functionalization of the heterocyclic substrates such as isoquinoline and quinoxaline. The scope of the methodology is now under investigation in our laboratories.

\section{ACKNOWLEDGEMENTS}

FAPESP, CNPq

\section{REFERENCES}

${ }^{1}$ Kondo, Y.; Shilai, H.; Uchiyama, M.; Sakamoto, T. J. Am. Chem. Soc. 1999, 121, 3539.

${ }^{2}$ Bresser, T.; Mosrin, M.; Monzon, G.; Knochel, P. J. Org. Chem. 2010, 75, 4686.

\footnotetext{
$15^{\text {th }}$ Brazilian Meeting on Organic Synthesis - $15^{\text {th }}$ BMOS - November 10-13, 2013 - Campos do Jordão, Brazil
} 